\section{TRAVESÍAS PELIGROSAS: LOS CAMINOS HACIA LA CIUDADANÍA*}

\section{DANGEROUS CROSSINGS: JOURNEYS TO CITIZENSHIP}

\author{
Phillip Cole \\ Social Ethics Research Centre \\ University of Wales, Newport
}

\begin{abstract}
In this paper I argue that citizenship and immigration policy in the United Kingdom, and other European powers, is informed by a postcolonial anxiety, informed by their colonial history. As far as the United Kingdom is concerned, the traveller from western Europe is civilized, and so welcome with no restrictions on access to the territory and with a shared European Union citizenship. The traveller from eastern Europe is less welcome. Travellers from beyond the European "frontier" face even more restrictions if they journey to the United Kingdom seeking national citizenship. Their journey has grown more hazardous during recent years, physically, politically and legally. While liberal political theory has "forgotten" its colonial past and writes about a world in which colonialism and slavery never happened, the UK's immigration and citizenship regulations seem unable to forget either the past or the colonial narrative that shaped how it was understood at the time. This paper examines the most recent developments in the UK's citizenship and immigration legislation and their likely future development against this background.
\end{abstract}

KEY WORDS: Citizenship; immigration; colonialism; global justice.

\section{INTRODUCCIÓN}

La idea de viajar más allá de las fronteras nacionales inspiró las narrativas coloniales durante la formación del Imperio Británico. Si viajar por Europa occidental tenía que ver con participar en la civilización europea, con la idea del Grand Tour, desplazarse a Europa del este era una empresa más caprichosa y se tornaba más peligrosa cuanto más al este se aventuraba uno. La travesía de Jonathan Harker al castillo de Drácula narrada en la novela de Bram Stoker capta parte de la incertidumbre que generaba esa región. Por su parte, viajar más allá de Europa era una aventura completamente distinta: ya no se estaban cruzando fronteras nacionales, sino la frontera hacia lo desconocido. En este mismo período, los viajeros de la "periferia" empren-
RESUMEN: En este artículo sostengo que la política de ciudadanía e inmigración en el Reino Unido, y en otras potencias europeas, está fundada en una ansiedad postcolonial, heredera de su historia colonial. Por lo que respecta al Reino Unido, el viajero de Europa occidental es civilizado $y$, por tanto, bienvenido, sin ninguna restricción de acceso al territorio y con la ciudadanía de la UE compartida. En cambio, no es tan bienvenido el viajero procedente de Europa del este. Los viajeros de más allá de la "frontera" europea se enfrentan incluso a un mayor número de restricciones si viajan al Reino Unido buscando la ciudadania nacional. Su viaje se ha hecho más peligroso durante los últimos años tanto físicamente como en términos políticos y legales. Mientras que la teoría política liberal ha "olvidado" su pasado colonial y escribe sobre un mundo en el que el colonialismo y la esclavitud nunca sucedieron, las regulaciones sobre inmigración y ciudadanía en el Reino Unido parecen incapaces de olvidar el pasado y la narrativa colonial que determinaron cómo dicho pasado fue comprendido en su momento. En este artículo examino los desarrollos más recientes en la legislación de ciudadanía e inmigración del Reino Unido y su probable desarrollo futuro en contraposición a estos antecedentes.

PALABRAS CLAVE: Ciudadanía; inmigración; colonialismo; justicia global.

dían sus propios periplos coloniales, a menudo impuestos por la esclavitud y el trabajo bajo contrato (indentured labour). Pero algunos hicieron libremente la travesía al "centro" del imperio y a finales del siglo XIX y a lo largo de todo el siglo XX el Reino Unido, por ejemplo, se convirtió en un foco para la inmigración colonial. Podemos ver, así, la narrativa colonial en sentido contrario, dado que los antiguos súbditos coloniales viajan al centro en busca de la ciudadanía nacional.

En lo que respecta al Reino Unido, los elementos clave de la historia colonial siguen en su sitio: el viajero de Europa occidental es civilizado, comparte la ciudadanía de la Unión Europea y, por tanto, es bienvenido sin ninguna restricción de acceso al territorio. El viajero procedente de Europa del 
este no es tan bienvenido. Incluso los que participan de la ciudadanía europea son considerados sospechosos y en algunos casos, por ejemplo, quienes proceden de Bulgaria y de la tierra de Drácula, Rumanía, tienen acceso restringido. Por último, los viajeros del otro lado de la "frontera" europea se enfrentan incluso a un mayor número de restricciones si se desplazan al Reino Unido buscando la ciudadanía nacional. Su viaje se ha vuelto más peligroso durante los últimos años tanto física como política y legalmente.

Este artículo analiza la forma en la que esta travesía hacia la ciudadanía del Reino Unido se está volviendo más difícil y contrapone sus obstáculos a los antecedentes de la narrativa colonial para mostrar cómo ésta delata la forma en la que el Reino Unido ve el mundo "exterior" y a los viajeros provenientes de él. Mientras que la teoría liberal ha "olvidado" su pasado colonial y escribe sobre un mundo en el que el colonialismo y la esclavitud nunca sucedieron, las regulaciones sobre inmigración y ciudadanía del Reino Unido parecen incapaces de olvidar ni el pasado ni la narrativa colonial que determinaron cómo dicho pasado fue comprendido en su momento. Pero en este artículo se emprende un viaje más largo. La teoría política liberal, tal y como se desarrolló durante el período de la expansión colonial, adoptó, al menos en su forma kantiana, una visión universal de la ética y la política, con el ideal del ciudadano universal que podia relacionarse con otros ciudadanos del mundo en el ámbito de un discurso racional libre e igual. Esta ciudadanía, asociada con el período ilustrado, atravesó las fronteras nacionales, pero estaba estructurada en torno a la exclusión del otro "irracional", que fue considerado incapaz de relacionarse en un discurso racional universal debido a su falta de "europeidad". Y, por tanto, esta concepción de la ciudadanía, aunque era aparentemente universal, fue construida a través de una exclusión velada de esos otros. Si bien el ideal de ciudadanía universal se puede entender como opuesto y superador de los límites de la ciudadanía nacional, la atracción de la ciudadanía nacional persistió, en parte como una respuesta a esta exclusión implícita, pues los pueblos a lo largo del mundo reivindicaban el derecho al reconocimiento político completo dentro de sus propios Estados-nación. Sin embargo, la ciudadanía nacional es explícitamente exclusiva y este aspecto exclusivo es el que las antiguas potencias coloniales aprovecharon para no incorporar a sus antiguos súbditos coloniales, de tal manera que sus prácticas de ciudadanía e inmigración han sido cada vez más caracterizadas por una ansiedad postcolonial.

Éste es el momento en el que nos encontramos ahora. Para superarlo necesitamos emprender el viaje hacia una ciudadanía global, una ciudadanía genuinamente inclusiva estructurada en torno a derechos políticos, sociales, económicos y culturales de carácter internacional. Estas estructuras de la ciudadanía global están en sus comienzos y el camino hacia ella parece profundamente arriesgado y supone cruzar la frontera conceptual prohibida del Estado-nación. Pero es un viaje que considero que debemos comprometernos a emprender.

\section{Cruzando fronteras}

Tradicionalmente la teoría política liberal asumía que se ocupaba de las relaciones entre los miembros de una comunidad politica particular: todas las cuestiones de justicia eran tratadas y resueltas entre ciudadanos iguales. La ausencia de un "exterior" puede ser entendida mediante la idea de la "ciudadanía universal". No había necesidad de proponer la existencia de un "exterior" de dicha comunidad política particular porque ésta era, en efecto, universal: las reglas y los procedimientos eran aquéllos que todos los agentes racionales libres e iguales aceptaban $y$, de este modo, por definición, eran los resultados de aquellas reglas y procedimientos. Durante el período de la ciudadanía nacional los teóricos liberales han tenido que admitir la existencia de un exterior constituido por otras comunidades políticas con otros ciudadanos. Este reconocimiento ha ocasionado dos respuestas. La primera es un enfoque cosmopolita, que extiende esas relaciones de justicia más allá de las fronteras y que ha dado lugar a un creciente corpus de obras que se ocupan de asuntos de justicia y ética global. La segunda respuesta es comunitarista y confina las relaciones de justicia a los miembros de "nuestra" comunidad política (excepto algunas obligaciones mínimas y "escasas"), normalmente entendida como una "nación", de esta manera rechaza la posibilidad de cualquier forma de moral y comunidad política universal.

La cuestión sobre cómo alguien se convierte en ciudadano ha sido raramente considerada en cualquiera de estos enfoques y éste es el objetivo del presente artículo. Podría ser tentador pensar que el acceso a la ciudadanía nacional 
es el acto relativamente simple de cruzar una sola frontera desde el exterior hacia el interior. Sin embargo, la cuestión del acceso a la ciudadanía nacional es mucho más compleja, ya que el "aspirante" a ciudadano debe cruzar un número diverso de fronteras y entrar en diferentes tipos de espacios políticos antes de llegar a la pertenencia completa. Estos espacios son: 1) residencia indocumentada o "ilegal"; 2) residencia legal pero temporal; 3) residencia permanente; 4) ciudadanía; y 5) identidad nacional. El Estado-nación puede interponer obstáculos en las fronteras de cada uno de estos espacios, y en realidad los propios migrantes pueden resistirse a "avanzar" a través de ellos: muchos migrantes prefieren permanecer indocumentados o sólo anhelan la residencia temporal; o si adquieren la residencia permanente puede que elijan no solicitar la ciudadanía; o habiendo adquirido la ciudadanía, puede que rechacen la "identidad nacional" dominante. El Reino Unido ha hecho que estas fronteras no sean fáciles de cruzar y está pensando en dificultar más ese proceso.

\section{Primera frontera}

La preocupación entre los Estados democráticos liberales por el flujo de migrantes indocumentados o "ilegales" hacia sus territorios se manifiesta en el aumento de las vallas y los centros de detención en y alrededor de sus territorios. Un reto importante al que se enfrentan es si el movimiento hacia fronteras más "seguras" es compatible con los valores de una democracia liberal y si no lo es, cómo pueden justificar la búsqueda de protección de sus valores democráticos liberales internos a través de controles fronterizos cada vez más iliberales (Cole 2006). K.M. Fierke apunta al nexo entre esta securitización de la migración y la europeización de las políticas de inmigración (Fierke, 2000: 112). La primera fuente de incertidumbre es el acceso a la asistencia social y la inquietud por la opción más ventajosa (venue shopping) para migrantes y refugiados. "Los migrantes son representados como un peligro para los recursos del Estado de bienestar y para la estabilidad socio-cultural de Europa" (Fierke, 2000: 112; Cole, 2007 y 2009). Además, el ataque en Nueva York el 11 de septiembre de 2001 ha conducido a mayores incertidumbres, a partir de las cuales "la seguridad se ha elevado por encima de las libertades individuales y colectivas" (Fierke, 2000: 113). Esto ha afectado no sólo a migrantes, sino también a ciudadanos nacionales, que ven sus libertades civiles tradicionales erosionadas por un estado de inquietud por la seguridad.
Los migrantes del Reino Unido actualmente se enfrentan a unos niveles de seguridad cada vez más estrictos que intentan bloquear el acceso indocumentado. En la actualidad tres cuartos de la población mundial necesita solicitar el visado para visitar dicho país y de acuerdo con la recientemente establecida Agencia de Fronteras del Reino Unido: "Forma parte de la acción del gobierno ampliar la red de visados para reforzar la seguridad fronteriza. Hoy día existe un triple anillo de seguridad protegiendo el Reino Unido: visados de huellas dactilares que encierran a las personas en una identidad, un sistema de fronteras de alta tecnología que comprueba si las personas están en listas de búsqueda y carnets de identidad para nacionales extranjeros" (Informe del Ministerio de Interior del Reino Unido). El objetivo establecido es hacer tan difícil acceder ilegalmente al Reino Unido, y tan opresivo si se accede de dicha manera, que los futuros inmigrantes indocumentados se desanimen a intentar el viaje (para un informe de las condiciones físicas en los centros de internamiento del Reino Unido, cf. Cole, 2006).

\section{Segunda frontera}

Aquellos migrantes documentados que deseen entrar en el Reino Unido temporalmente también se enfrentan a controles más duros. En 2008 se introdujo un sistema de puntos que se ocupa de los migrantes procedentes del exterior del Área Económica Europea (AEE), que ahora tienen que aprobar una evaluación basada en puntos. Hay cinco categorías diferentes y el número de puntos que necesitan los migrantes depende de la categoría que estén solicitando. Los puntos son concedidos en base a la habilidad, la experiencia, la edad y el nivel de necesidad en el sector donde el migrante vaya a trabajar. Las categorías son:

1. Trabajadores altamente cualificados, por ejemplo: científicos y empresarios (los ejemplos son proporcionados por la Agencia de Fronteras del Reino Unido);

2. Trabajadores cualificados con una oferta de trabajo, por ejemplo: profesores y enfermeras;

3. Trabajadores poco cualificados que cubren escasez de mano de obra eventual y específica, por ejemplo: trabajadores de la construcción en un proyecto particular;

4. Estudiantes;

ARBOR CLXXXVI 744 julio-agosto [2010] 615-624 ISSN: 0210-1963

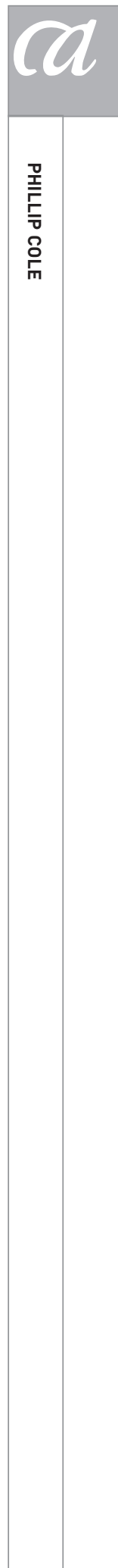

617 
5. Movilidad juvenil y trabajadores temporales, por ejemplo: músicos que vayan a actuar en un concierto.

A excepción de la primera categoría, todos los migrantes necesitan un patrocinador, y las organizaciones deben adquirir una licencia de patrocinio. Éstas también tienen que encargarse de los migrantes mientras están en el Reino Unido: por ejemplo, en el caso de los músicos visitantes, el patrocinador debe estar dispuesto a responsabilizarse de ellos y responder de todas sus actividades mientras se encuentren en el Reino Unido. El sistema de puntos da al gobierno poderes mucho más fuertes para controlar la inmigración del exterior del $A E E$, y a través de la manipulación de los criterios puede decidir cuántos migrantes serán admitidos en cada categoría. Incluso se ha suspendido la categoría 3, prohibiendo de forma efectiva la movilidad legal de los migrantes económicos sin cualificar procedentes del exterior del AEE.

\section{Tercera frontera}

Tradicionalmente el permiso indefinido de residencia o la residencia permanente en el Reino Unido se ha obtenido cumpliendo con un requisito temporal. Los nacionales de la UE adquirian la residencia permanente tras cinco años de residencia en el Reino Unido. Los no nacionales de la UE adquirian el Permiso Indefinido de Residencia (ILR en sus siglas inglesas) después de estar con un permiso de trabajo durante cinco años; también el cónyuge o pareja civil tenía derecho a solicitar el permiso indefinido de residencia después de estar dos años en el Reino Unido con motivo de dicha relación. Sin embargo, con las nuevas propuestas obtener el ILR se ha hecho más difícil. El dos de abril de 2007 se introdujeron nuevos requisitos para los solicitantes como conocer la lengua y el estilo de vida del Reino Unido. Para satisfacer estos requisitos es necesario hacer en inglés el examen "Life in the UK" o asistir a un curso acreditado de Inglés como Segunda Lengua (ESOL en sus siglas inglesas) que se enseña utilizando materiales sobre la ciudadanía y el estilo de vida en el Reino Unido.

\section{Cuarta frontera}

La barrera alrededor de la ciudadanía nacional del Reino Unido ha sido profundamente troquelada por la narrativa colonial que describi en la primera parte de este artículo. En general, la ciudadanía puede ser adquirida por dos vías distintas: por nacimiento y por inmigración. La ciudadanía por nacimiento puede, a su vez, adquirirse de dos formas diferentes: habiendo nacido dentro del territorio del Estado (jus soli); o habiendo nacido de padres de los cuales al menos uno es ciudadano (jus sanguinis). En lo referente a la adquisición de ciudadanía por nacimiento, el Reino Unido se ha movido entre el jus soliy el jus sanguinis y este movimiento ha estado motivado por una preocupación por su historia colonial. Los ciudadanos de los territorios coloniales y de los Estados independientes miembros de la Commonwealth eran, en efecto, todos súbditos británicos y todos tenian derecho a entrar en el Reino Unido. La Ley de Nacionalidad de 1948 creó la ciudadanía del Reino Unido y Colonias que podía ser adquirida por súbditos británicos bajo determinadas condiciones y mientras que al principio la entrada al Reino Unido continuó siendo automática para todos los súbditos británicos, esta maniobra abrió la vía a futuras restricciones: los ciudadanos de la Commonwealth perdieron su derecho de entrada en 1962 y los ciudadanos del Reino Unido y la Commonwealth perdieron el suyo en 1968. Una peculiaridad de la forma en que estaba regulada la nacionalidad británica y las leyes de inmigración, fue que durante este período se separaron tanto que la ciudadanía británica no daba el derecho de entrada a ciertos grupos. Éstas se pusieron de acuerdo con la Ley de Nacionalidad de 1981, pero eso le convirtió en una de las ciudadanías más complejas de cualquier lugar del mundo. La ley de 1981 creó formalmente múltiples niveles de pertenencia al Reino Unido:

i) Ciudadanía británica

ii) Ciudadanía británica de territorios dependientes (BDTC en sus siglas inglesas)

iii) Ciudadanía británica de territorios extranjeros (BOC en sus siglas inglesas)

iv) Nacional británico (en el extranjero)

v) Súbdito británico

vi) Persona bajo protección británica

vii) Ciudadano de la Commonwealth

viii) Ciudadano de Irlanda

Sólo la primera categoría tenía derecho automático de entrada y el resto de las clasificaciones son más o menos jerárquicas en su nivel de acceso. Según el derecho europeo, los nacionales de la UE actualmente se encuentran en segundo lugar en términos del derecho de acceso, con más derechos que dos clasificaciones de ciudadanos británicos. 
Como hemos visto, el propósito de la ley de 1981 era poner de acuerdo la ciudadanía británica con las leyes de inmigración aprobadas entre 1962 y 1971, que habian generado una situación en la que el Reino Unido negaba la entrada a sus propios ciudadanos. La ley de 1981 resolvió el problema negando la ciudadanía plena a aquellos grupos que "daba la casualidad" que eran predominantemente negros. Según Anne Owers,

"... la ley de nacionalidad tenía que ver con reducir la posibilidad de inmigración, especialmente la inmigración negra. Esta prioridad significa que buena parte de la ley de nacionalidad meramente codificó y paralizó la legislación británica en materia de inmigración. Sus disposiciones estaban dominadas por un miedo a quien pudiese ser capaz de venir" (Owers, 1984: 6).

Sin embargo, más que simplemente despojar de la ciudadanía británica a los antiguos ciudadanos del Reino Unido y la Commonwealth que habian sido privados de los derechos de entrada según las leyes de inmigración, la ley de 1981 les dio una clase de ciudadanía británica, pero una degradada -se crearon las clasificaciones de BDTC y BOC-, una ciudadanía británica que no daba derecho a entrar en Gran Bretaña. Vaughan Bevan afirma:

"Mientras que BDTC y BOC perpetúan, en términos formales, las responsabilidades de la Commonwealth del Reino Unido, virtualmente no tuvieron ningún significado en el derecho interno, ya que no suponían el derecho de entrada al Reino Unido... Son conceptos cosméticos diseñados para aplacar la opinión local e interna" (Bevan, 1986: 129).

Kathleen Paul resume la experiencia británica: "En este proceso, las definiciones formales de ciudadanía han tenido cada vez menos influencia que las imágenes racializadas de la identidad nacional" (Paul, 1997: 189).

Además del nacimiento, otro método de adquisición de la ciudadanía es a través de inmigración, normalmente a través del cumplimiento de requisitos de residencia. Hemos visto más arriba cómo aquéllos que buscan permiso indefinido de residencia se enfrentan a nuevas barreras debido al requisito de superar un test. Esta estructura de exámenes es parte de una barrera nueva y en desarrollo que también marca el acceso a la ciudadanía nacional me- diante inmigración. El test de ciudadanía, u oficialmente el test "Life in the UK", fue introducido en 2004, junto con la ceremonia de ciudadanía. Todos los nacionales extranjeros que tengan 18 años o más que soliciten ser ciudadanos británicos o el permiso indefinido de residencia tienen que hacer un examen para demostrar que han alcanzado un nivel de conocimiento del estilo de vida y la lengua del Reino Unido considerado apropiado para la ciudadanía. El test de ciudadanía lo realizan quienes ya tienen unas habilidades moderadas en lengua inglesa (el galés y el gaélico se aceptan en Gales y Escocia); los demás deben cumplir los requisitos asistiendo a un curso combinado de clases de lengua y ciudadanía. Si aprueban el examen, los solicitantes deben asistir a una ceremonia de ciudadanía en la que prestan juramento de lealtad: sólo entonces reciben el certificado de naturalización. Deben asistir a la ceremonia en los noventa dias siguientes a la recepción de la invitación para llevarla a cabo. En ella deben hacer un juramento de lealtad -jurando lealtad a la Monarquia- y una promesa de respeto y defensa de las leyes y los valores del Reino Unido. Al final de la ceremonia se escucha el himno nacional y se exige a todos que permanezcan de pie para mostrar su respeto por el Reino Unido y la Monarquía.

El concepto "ciudadanía merecida" inspira las propuestas para una reforma adicional contenida en el informe del gobierno The path to citizenship: next steps in Reforming the Immigration System (El camino hacia la ciudadanía: próximos pasos en la reforma del sistema de inmigración) publicado en febrero de 2008. La idea que hay detrás de las nuevas propuestas es que antes de que un nacional extranjero pueda ser ciudadano británico, o residente permanente, debe ser capaz de demostrar que se ha "merecido el derecho a quedarse". Esto sustituye la práctica previa que permitía a las personas solicitar la ciudadanía a partir de su residencia continuada en el Reino Unido, sin tener que demostrar que podían hablar inglés (o galés o gaélico) o que tenían alguna participación en la vida británica. Las habilidades lingüísticas son, como hemos visto, una parte del test de ciudadanía, pero las nuevas propuestas irian más lejos ya que requieren a los solicitantes que demuestren una contribución actual a la vida del Reino Unido, incluyendo la contribución a un fondo para ayudar a que las comunidades en el Reino Unido hagan frente al impacto de la inmigración. Habrá tres grados con las nuevas propuestas: 1) residencia temporal durante un pe- 
ríodo determinado; 2) ciudadanía de prueba, 3) ciudadanía británica/residencia permanente. El período de prueba es la clave para la idea de la ciudadanía "merecida". El documento identifica cuatro formas en las que un migrante puede ascender de grado: mejorando el dominio de la lengua inglesa; trabajando intensamente y pagando impuestos; obedeciendo la ley, y demostrando una ciudadanía activa (Home Office, 2008: 25). Por ejemplo, mientras que los solicitantes que hagan trabajos voluntarios verán recortado su periodo de prueba, éste podrá ser ampliado para aquéllos que cometan infracciones criminales menores. Por su parte, los solicitantes que tengan sentencias de prisión perderán su derecho a la ciudadanía. The path to Citizenship también reivindica que el objetivo clave es "poner los valores británicos en el corazón del sistema de inmigración" (Home Office, 2008: 17).

\section{Quinta frontera}

Este empeño en colocar los valores británicos en el corazón del sistema de inmigración indica la quinta frontera que el "aspirante" a ciudadano debe sortear, la de la identidad nacional. Un migrante puede superar satisfactoriamente los otros cuatro espacios y por tanto obtener la ciudadanía legal, pero aun así ver rechazado su pleno reconocimiento como un miembro del Estado-nación porque no está de acuerdo con el contenido de la identidad nacional dominante. Esto tendrá un efecto en la libertad y efectividad con la que pueda acceder a la esfera pública de la ciudadanía política y también afecta a su acceso a instituciones encargadas de la salud, la asistencia social y la educación. Pero una fuente de preocupación adicional es que la atención prestada a la identidad nacional, si es adoptada por el Estado, puede determinar el proceso entero de adquisición de la ciudadanía afectando al acceso a la residencia temporal, a la residencia permanente y a la propia ciudadanía. Además de determinar el proceso legal de adquisición de la ciudadanía, el Estado podría continuar imponiendo conscientemente una narrativa de la identidad nacional en muchas de sus instituciones, por ejemplo, en la educación y el patrimonio cultural. El Reino Unido, como hemos visto, tiene un gran afán por hacer constar la "britaneidad" en sus normas de ciudadanía y al mismo tiempo está preocupado por que esa "britaneidad" esté representada en muchas de sus instituciones culturales (para una descripción del impacto de esta inquietud en el sector de patrimonio del Reino Unido, cf. Little y Naidoo, 2005).

\section{EL OLVIDO LIBERAL}

Hemos visto cómo el régimen de inmigración y ciudadanía en el Reino Unido "recuerda" vívidamente su pasado colonial. Por el contrario, la teoría política liberal tiene una tendencia al olvido cuando trata la historia del colonialismo europeo y la esclavitud. Al igual que solia plantear cuestiones de justicia dentro de una comunidad política de ciudadanos libres e iguales sin una noción de lo que quedaba fuera de dicha comunidad, cuando trata cuestiones de justicia global lo hace en un mundo donde el colonialismo y la esclavitud nunca tuvieron lugar. Reconoce las desigualdades globales, en realidad puede dedicarse apasionadamente a ellas, pero tiende a no situar esas desigualdades en el contexto de la historia europea. Por tanto, una respuesta común a la desigualdad global es sostener que, más que tener una obligación de permitir a los migrantes de las antiguas colonias el acceso a sus estructuras de ciudadanía nacional, la única obligación ética es intentar mejorar la pobreza global a través de la redistribución de recursos: no podemos derivar un derecho a la libertad de circulación internacional a partir del hecho de la desigualdad global. Sin embargo, si situamos esa desigualdad global dentro del contexto de la historia colonial, proveniente de una época en la que los ciudadanos europeos se sentian libres de viajar por el mundo para explotar recursos y oprimir pueblos en cualquier lugar, entonces el rechazo a reconocer un derecho a la libertad de circulación cuando el viaje es en sentido contrario parece indefendible. Por supuesto, eliminando el contexto histórico, este rechazo tiene la apariencia de la imparcialidad liberal, ya que es impuesta sobre todas las personas, pero la perspectiva postcolonial revela que está muy lejos de ser imparcial.

La teoría liberal parece asumir que la injusta relación entre el "interior" y el "exterior" político es tal que puede ser corregida sin abordar las estructuras de poder que determinaron esa relación y que han sido sedimentadas a través de los procesos históricos de colonialismo y neocolonialismo. Peter Childs y Patrick Williams apuntan a la escala de la experiencia colonial: el poder colonial europeo duró, de formas diversas, desde el siglo XVI hasta la segunda mitad del siglo XX y "constituye un fenómeno sin precedentes y con repercusiones globales en el mundo contemporáneo" (Childs y Williams, 1997: 2). Pero no se puede considerar que la expresión "postcolonial" implique 
que la experiencia colonial haya terminado: "existen formas importantes en las que el control europeo está muy presente" (Childs y Williams, 1997: 5). Ellos destacan la opinión de Gayatry Spivak: "Vivimos en un mundo postcoIonial neocolonizado" (Spivak, 1990: 166, citado en Childs y Williams, 1997: 7).

Sin embargo, debemos ser cautos a la hora de reivindicar que la teoría liberal "olvidó" su historia colonial, porque no es literalmente cierto. Los teóricos liberales durante el período de la llustración fueron muy conscientes de que otros habitaban el globo y mantuvieron una opinión estricta sobre su naturaleza; esa naturaleza, sostenían, era tal que les excluía del círculo de la ciudadanía. Pero aunque la teoría política guardó silencio al respecto, su propia estructura daba cuenta de su presencia. Las teorías de la libertad, la justicia y la propiedad tomaron la forma de una aparente universalidad pero con una estructura diseñada para excluir a los otros, una estructura basada en la visión de la teoría liberal sobre su esencia natural. Esto era, por tanto, una universalidad exclusiva, una universalidad construida en torno a una concepción de cómo eran los seres humanos plenos y, por tanto, diseñada para excluir a aquellos seres humanos que no fuesen capaces de cumplir dicha concepción. Vemos aquí que la concepción universal de ciudadanía nunca pretendió incluir a todo el mundo, sino sólo a aquéllos capaces del debate racional que constituía tal ciudadanía.

De hecho, las versiones más tempranas de la tradición liberal fueron explícitas sobre esta exclusión. La humanidad europea fue tomada como universal, en la medida en la que todos los no-europeos no estaban cualificados para la inclusión dentro de la pertenencia política: eran incapaces de participar en el discurso moral. Emmanuel Chukwudi Eze investiga esta exclusión en la obra de Kant (Eze, 1997a). Según Kant, sostiene Eze, los pueblos no europeos: "... están desprovistos de principios éticos porque esos pueblos carecen de capacidad para el desarrollo del "carácter" y no tienen carácter presumiblemente porque carecen de autoconciencia adecuada y de voluntad racional" (Eze, 1997a: 115). Para Kant: "... la diferencia de talentos naturales entre varias naciones no puede ser completamente explicada por medio de explicaciones causales [externas, físicas, climáticas], sino que más bien reside en la naturaleza [moral] del propio Hombre" (Eze, 1997a: 115-116).
Kant concluye que los nativos americanos no pueden ser educados en absoluto; los africanos pueden ser "entrenados" sólo como esclavos o sirvientes; y los asiáticos pueden ser educados en las artes, pero no en las ciencias: "Nunca pueden alcanzar el nivel de los conceptos abstractos" (Eze, 1997a: 117). Hay otros ejemplos de esta exclusión explícita de los no europeos de la plena humanidad: Kant una vez más en Observaciones sobre el sentimiento de lo bello y lo sublime (Kant, 1950 y 1960), el ensayo de David Hume "Sobre el carácter nacional" (Hume, 1964) y el tratamiento de John Locke a los nativos americanos y su carencia de derechos de propiedad (Lebovic, 1991: 260-261). En el centro de la filosofía política occidental está el ideal del sujeto autónomo, capaz de auto-legislarse y, por tanto, de ser incluido en un ideal universal de ciudadanía política. Fuera de este ámbito de discurso racional libre e igual estaba el extranjero no europeo, naturalmente limitado en su capacidad de autonomía e incapaz de participar en esta ciudadanía universal. Por consiguiente, se abrió el espacio para la esclavitud y el colonialismo. Eze afirma:

"... desde que para los filósofos de la llustración la humanidad europea era no sólo universal, sino la encarnación de, y la coincidencia con, la humanidad como tal, enmarcar al africano como ser de una especie diferente, subhumana, sancionaba por tanto antropológica y filosóficamente la explotación de los africanos mediante formas brutales que no estaban permitidas para los europeos" (Eze, 1997b: 7).

Sin embargo, mientras que la acusación de silencio sobre el estatus de los no europeos no es, por tanto, literalmente cierta en la teoría liberal, las otras dos acusaciones sí que lo son. La primera, que esta tradición estructuró sus principios esenciales a partir de la exclusión de los no europeos del ideal de la ciudadanía universal. La segunda, que la teoría liberal contemporánea confabula con esa exclusión explícita no haciendo mención a este aspecto de su historia: Ios pasajes de este tipo en la obra de Locke, Hume, Kant y otros no son reconocidos por tanto, y ha sido ignorado su papel en la justificación del colonialismo y la esclavitud. Como comentaba más arriba, lo que podemos decir desde estas obras coetáneas es que el colonialismo y la esclavitud nunca ocurrieron en absoluto. La teoría liberal contemporánea podría ser caracterizada justificadamente como una vasta acción de olvido racializado. Si tomamos en serio esta historia puede ser que necesitemos una teoría política fundamentalmente diferente, con concepciones

ARBOR CLXXXVI 744 julio-agosto [2010] 615-624 ISSN: 0210-1963

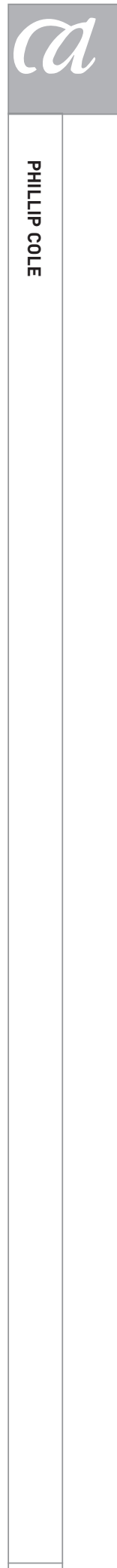


radicalmente transformadas de la libertad, la justicia, la autonomía y la igualdad.

\section{Ansiedad postcolonial}

El ideal de ciudadanía universal tuvo, por supuesto, una dimensión progresista. Fue el producto de la creencia ilustrada en el poder de la razón y en la igualdad moral fundamental de todos los seres racionales y tuvo que jugar un papel revolucionario en la crítica y el derrocamiento de un régimen basado en el gobierno aristocrático. La relación entre el ideal de ciudadanía universal -incorporada en la noción de derechos del "hombre" y en la igualdad moral de todos los sujetos humanos- y la ciudadanía nacional era compleja. Aquí el único punto que tomaría en consideración de esta relación es que la crítica revolucionaria de este ideal ilustrado -con su confinamiento a un subconjunto estrecho de europeos occidentales y su justificación del imperialismo y colonialismo- dio un nuevo ímpetu radical al concepto de ciudadanía nacional. La ciudadanía nacional, entonces, emerge dialécticamente del ideal de ciudadanía universal en una nueva forma más radical. Sin embargo, mientras que el movimiento dialéctico puede ser percibido como políticamente progresista con el derrocamiento de los imperios coloniales, parte del movimiento dialéctico es la explicitación de las dimensiones ocultas y exclusivas de la ciudadanía. Al reclamar la ciudadanía nacional un pueblo reclama el derecho a trazar una frontera explícita de exclusión.

Esto, por sí mismo, no es necesariamente problemático si la frontera puede ser trazada de manera que respete la común humanidad que se reconoce a todas las personas. Sin embargo, la ciudadanía nacional tiene su propia dimensión negativa que descansa en este potencial reivindicado de exclusión. En primer lugar, la ciudadanía nacional trae consigo el Estado-nación, el cuerpo soberano que reivindica ejercer ese poder, y los Estados-nación son extremadamente reacios a reconocer ningún límite sobre sus poderes soberanos, haciendo muy remota la posibilidad de una regulación global de los regímenes migratorios y las prácticas de ciudadanía. En segundo lugar, el concepto de identidad nacional trae consigo la reivindicación de un conjunto de características distintivas que identifican este cuerpo de personas como una nación y por tanto les otorga el derecho a un Estado-nación. La reivindicación de ciudadanía nacional a menudo puede ser subvertida en una reivindicación de superioridad nacional, que en ocasiones recupera el derecho a reclamar el control sobre otros pueblos de nacionalidad inferior y sus recursos. Esta expresión de "superioridad nacional" en la era moderna ha igualado, y en ocasiones excedido, las brutalidades de la época ilustrada.

Lo más relevante en esta discusión es el hecho de que los antiguos poderes coloniales de Europa estuvieron tan preocupados como sus antiguos súbditos coloniales en reclamar la ciudadanía nacional para su pueblo, pero en este caso la preocupación principal no era reivindicar la soberanía política -ellos ya la poseían-, sino protegerse a sí mismos contra los antiguos súbditos coloniales. $Y$ por tanto las prácticas de ciudadanía e inmigración del Reino Unido, por ejemplo, han estado inspiradas cada vez más por esta ansiedad postcolonial. Al igual que los ideales ilustrados de libertad, igualdad, propiedad, etc., fueron conformados por el hecho de quién era excluido de tales ideales, la práctica de la ciudadanía nacional está conformada por el hecho de quién es excluido de la misma.

A pesar de los obstáculos situados en este camino, ha habido migraciones significativas desde las antiguas colonias hacia el centro colonial, y esto significa que la historia colonial no sólo conforma las relaciones entre el "interior" y el "exterior", sino que también conforma las relaciones entre los miembros de una sola comunidad política. Homi Bhabha sostiene que esta llegada de pueblos postcoloniales al territorio de la antigua potencia colonial tiene un profundo impacto en cómo ese centro se concibe a sí mismo y a los otros, y debería, por tanto, tener un profundo impacto en la filosofía política occidental. Bhabha afirma que "la perspectiva postcolonial nos fuerza a repensar las limitaciones profundas de un sentido de comunidad 'liberal' consensuado y colusorio" (Bhabha, 1990: 219). Si tomamos tal perspectiva postcolonial, la relación entre el interior y el "exterior constitutivo" se convierte en la cuestión central para cualquier teoría política, con la inmigración y el acceso a la ciudadanía como los puntos en los que se expresan las tensiones suscitadas por esta cuestión. Las nociones de ciudadanía nacional, identidad nacional y el Estado-nación se convierten en altamente problemáticas. 


\section{De la ciudadanía nacional a la ciudadanía GLOBAL}

Una posible respuesta consiste en trasladar el foco de atención al nivel global. Hay quien sostiene que la importancia de la ciudadanía vinculada al Estado-nación está ya en declive. Por ejemplo, David Jacobson afirma: "Bajo el impacto del movimiento transnacional de personas y su reforma de la manera en la que está constituida la comunidad social y política, el Estado-nación se está 'deshaciendo'" (Jacobson, 1997: 133).

El camino a seguir, de acuerdo con tal punto de vista, es tomar una perspectiva global e incrementar el alcance y el poder de los derechos de ciudadanía internacionales, más que los nacionales: la emergencia de un "orden constitucional internacional basado en los derechos humanos" (Jacobson, 1997: 136). Nos movemos desde una ciudadanía nacional a una ciudadanía global. Este enfoque global, por supuesto, debe ser considerado en el contexto de un crecimiento mucho menos favorable para el capitalismo global y las desigualdades globales de riqueza y poder. Junto a la decadencia de la soberanía nacional a la que Jacobson y otros han dado la bienvenida vemos el aumento de poder de corporaciones como la Organización Mundial del Comercio, comprometida con la protección del libre mercado, no con los derechos humanos. Este aspecto de la globalización, como ha observado David Theo Goldberg, tiene "implicaciones estructurales profundas" tanto para las antiguas colonias como para los "poderes geopolíticos colonizadores y dominantes" (Goldberg, 1997: 136).
Sin embargo, hay una atracción inevitable hacia un orden en el que los individuos y grupos tengan su integridad protegida por regímenes de derechos internacionales más que el tener que depender de los derechos conferidos por un Estado-nación que, debido a su historia, no a la de aquéllos, los puede considerar extranjeros, peligrosos y no deseados. Hemos visto más arriba cómo el aumento de la securitización de la inmigración está erosionando los derechos de los migrantes y haciendo más difícil y peligroso que nunca el camino hacia la ciudadanía nacional. No sólo eso, sino que la propia ciudadanía nacional se hace cada vez más insegura para quienes la poseen. Durante años de incremento de la tensión sobre la seguridad, dice Fierke: "la seguridad interna y externa empieza a fusionarse..." (Fierke, 2000: 114); y "... la posibilidad de una esfera dentro de la frontera entre el ciudadano y el migrante se desdibuja fácilmente, como tal, lejos de una clara distinción entre ciudadanos seguros y migrantes inseguros, 0 ciudadanos inseguros y migrantes amenazadores, aparece un ambiente de miedo generalizado" (Fierke 2000: 115). El hecho es que los derechos tradicionales y las libertades de la ciudadanía nacional están siendo erosionados en el Reino Unido en nombre de la seguridad. Bien podríamos ver que todos estamos en el mismo barco, seamos ciudadanos o migrantes, frente a gobiernos nacionales ansiosos de quitarnos nuestros derechos y libertades en favor de nuevas ansiedades combinadas con otras anteriores. Tanto la ciudadanía nacional como las poblaciones migrantes pueden encontrar una causa común al buscar una ciudadanía global como la mejor expresión de su identidad política.

\section{NOTAS}

* Agradezco la lectura y los comentarios de Gideon Calder, Jonathan Seglow y Noelia González Cámara a versiones anteriores de este artículo. La traducción del texto inglés ha sido realizada por Noelia González Cámara.

\section{BIBLIOGRAFÍA}

Bevan, Vaughan (1986): The Development of British Immigration Law, Croom Helm, Londres.

Bhabha, Homi (1990): "The Third Space: Interview with Homi Bhabha", en Jonathan Rutherford ed. Identity: Com-
Aceptado: 25 de mayo de 2009

doi: 10.3989/arbor.2010.744n1221 
munity, Culture, Difference, Lawrence and Wishart, Londres.

Childs, Peter y Williams, Patrick (1997): An Introduction to Post-Colonial Theory, Prentice Hall Harvester Wheatsheaf, Londres.

Cole, Phillip (2000): Philosophies of Exclusion: Liberal Political Theory and Immigration, Edinburgh U.P., Edimburgo.

- (2006): The Myth of Evil, Edinburgh U.P., Edimburgo.

- (2007): "Human rights and the national interest: migrants, health care and social justice", Journal of Medical Ethics, vol. 33, n. ${ }^{\circ} 5$.

- (2009): "Migration and the Human Right to Health", Cambridge Quarterly of Healthcare Ethics, vol. 18, n. ${ }^{\circ} 1$ enero, pp. 70-77.

Eze, Emmanuel Chukwudi (1997a): "The Color of Reason: The Idea of 'Race' in Kant's Anthropology", en E. C. Eze (ed.), Postcolonial African Philosophy: A Critical reader, Blackwell Publishers, Oxford y Cambridge.
- (1997b): "Introduction: Philosophy and the (Post)colonial" en E. C. Ede (ed.), Postcolonial African Philosophy: A Critical reader, Blackwell Publishers Ltd., Oxford y Cambridge.

Fierke, Karin M. (2000): Critical Approaches to International Security, Polity, Cambridge.

Goldberg, David Theo (1997): Racial Subjects: Writing on Race in America, Routledge, Londres.

Home office (2008): The Path to Citizenship: Next Steps in Reforming the Immigration System (HMSO).

Hume, David (1964): "Of National Characters", en T. H. Green y T. H. Grose III (eds.), Philosophical Works, Scientia Veralg, Aalen.

Jacobson, David (1997): Rights Across Borders: Immigration and the Decline of Citizenship, John Hopkins U.P., Baltimore y Londres.

Kant, Immanuel (1950): "On the Different Races of Man", en E. W. Count (ed.), This is Race, Henry Schuman, Nueva York.
- (1960): Observations on the Feeling of the Beautiful and the Sublime, traducc. J. L. Goldthwait, University of California Press, Berkeley.

Lebovic, Herman (1991): "The Uses of America in Locke's Second Treatise of Government" en R. Ashcraft (ed.), Locke: Critical Assessments, vol. 3, Routledge, Londres.

Littler, Jo and Naidoo, Roshi (2005): The Politics of Heritage: The Legacies of "Race", Routledge, Londres y Nueva York.

Owers, Anne (1984): Sheep and Goats: British Nationality Law and its Effects, Ludo Press, Londres.

Paul, Kathleen (1997): Whitewashing Britain: Race and Citizenship in the Postwar Era, Cornell U.P., Ithaca y Londres.

Spivak, Gayatri Chakravorty (1990): The Post-Colonial Critic: Interviews, Strategies, Dialogues, ed. S. Harasym, Routledge, Londres. 